\title{
Method for Identifying Eddy-Current Displacement Sensor
}

\author{
Mizuno Tsutomu', Goto Sho ${ }^{1}$, Deguchi Kenta ${ }^{1}$, Kitamura Yoshinori ${ }^{1}$, Asato Yuichi ${ }^{1}$ \\ Enoki Shigemi ${ }^{2}$, Shinagawa Hiroki ${ }^{2}$ \\ ${ }^{1}$ Faculty of Engineering, Shinshu University, Nagano 380-8553, Japan \\ ${ }^{2}$ SHINKAWA Sensor Technology, Hirosima 739-0153, Japan
}

\begin{abstract}
Eddy-current (EC) displacement sensors are used in a device for measuring the shaft vibration of turbines. When only the impedance/output voltage $(Z / V)$ converter breaks down, it is necessary to change it with an appropriate $Z / V$ converter by stopping and dismantling the power plant using the discriminant of the sensor probe installed in the neighborhood of the turbine shaft. In this paper, we describe a method for identifying the type of the sensor probe and the displacement $x$ from the measuring object to the coil by measuring the impedance characteristics of the sensor probe.
\end{abstract}

Index Terms - Eddy- current displacement sensor, identification method, maximum quality factor, frequency, displacement.

\section{INTRODUCTION}

$\mathrm{E}$ ddy-current (EC) displacement sensors are used in a device for measuring the shaft vibration of turbines. An EC displacement sensor is composed of a coil, an impedance/output voltage $(Z / V)$ converter and a coaxial cable that connects the coil and the $Z / V$ converter [1]. Currently, in the U.S.A., private management companies, which are different from electric power companies, are responsible for the maintenance and management of the EC displacement sensor. Therefore, it is difficult to rapidly respond to problems related to the EC displacement sensor.

The breakdown probability of a $Z / V$ converter composed of an electronic component is higher than that of a sensor probe composed of a coil and a coaxial cable. For this reason, when only the $Z / V$ converter breaks down, it is necessary to change it with an appropriate $Z / V$ converter by stopping and dismantling the power plant using the discriminant of the sensor probe installed in the neighborhood of the turbine shaft. However, the supply of electric power becomes unstable when the power plant is stopped and the cost for dismantling the plant increases.

In this paper, we describe a method for identifying the type of the sensor and the displacement $x$ from the measuring object to the coil by measuring the impedance characteristics of the sensor probe. It is necessary that the $Z / V$ converter adjusts the parameter according to the impedance of the sensor probe. Since the impedance changes with the displacement $x$, it is necessary to identify the displacement $x$.

In this paper, we describe

(1) a method for identifying the type of the sensor probe,

(2) a method for identifying the displacement $x$.

\section{IDENTIFICATION PRINCIPLE}

Fig. 1 shows the structure of the EC displacement sensor. The coil with the number of turns $N$ is placed it at the sensor tip. The coil and $Z / V$ converter are connected by a coaxial cable. In this study, we used sensor probes with the coaxial cable lengths $l_{\mathrm{ca}}=5 \mathrm{~m}$ and $9 \mathrm{~m}$ in the power plant. The

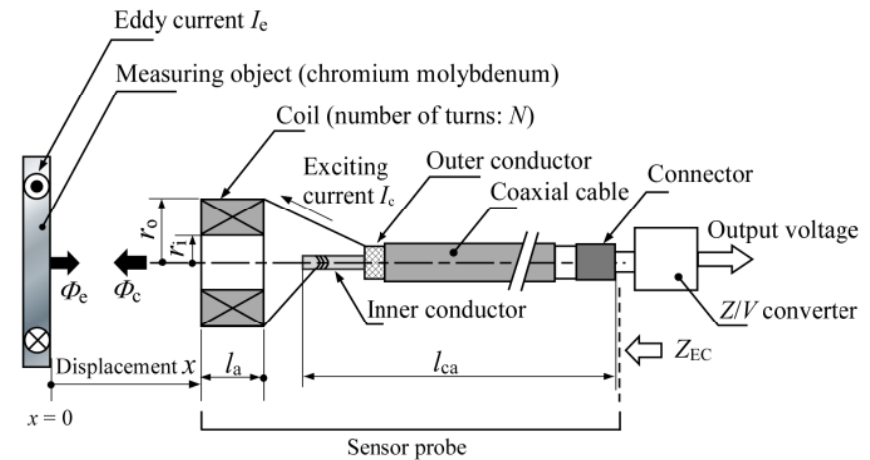

Fig. 1. Structure of EC displacement sensor (unit : $\mathrm{mm}$ ).

TABLE I

Structures of three types of sensor coils.

\begin{tabular}{l|l||c|c|c}
\multicolumn{5}{c}{ Structures of three types of sensor coils. } \\
\hline \hline \multirow{2}{*}{$\begin{array}{l}\text { Item } \\
\text { Dimensions }\end{array}$} & $l_{\mathrm{a}}$ & 2.2 & 2.2 & 2.1 \\
\cline { 2 - 5 } & $r_{\mathrm{i}}$ & 1.7 & 0.9 & 0.9 \\
\cline { 2 - 5 } & $r_{\mathrm{o}}$ & 2.3 & 2.5 & 2.7 \\
\hline \multicolumn{2}{l|}{ Number of turns, $N$} & 102 & 149 & 137 \\
\hline \hline
\end{tabular}

measuring object is made of chromium molybdenum steel, which is the shaft material of the generator and steam turbine. The chromium molybdenum steel administered the heat treatment of annealing [2]. The flux $\Phi_{\mathrm{c}}$ is produced when the exciting current $I_{\mathrm{c}}$ flows to the coil. The flux $\Phi_{\mathrm{c}}$ changes with the structure of each sensor probe. When the flux $\Phi_{\mathrm{c}}$ affects the measuring object, the eddy current $I_{\mathrm{e}}$ flows to this object and the flux $\Phi_{\mathrm{e}}$ arises in the direction that cancels the flux $\Phi_{\mathrm{c}}$. Therefore, when the flux $\Phi_{\mathrm{e}}$ changes with the displacement $x$, the resistance and inductance of the coil also change with the displacement $x$.

TABLE I shows the structual parameters of the coil. Three types of sensor probes which the structure of the coil and coaxial cable differ were produced experimentally, and the type of the sensor probe is identified on the basis of the impedance characteristics of the sensor probe. The structures of the coil and coaxial cable differ in each sensor probe. 


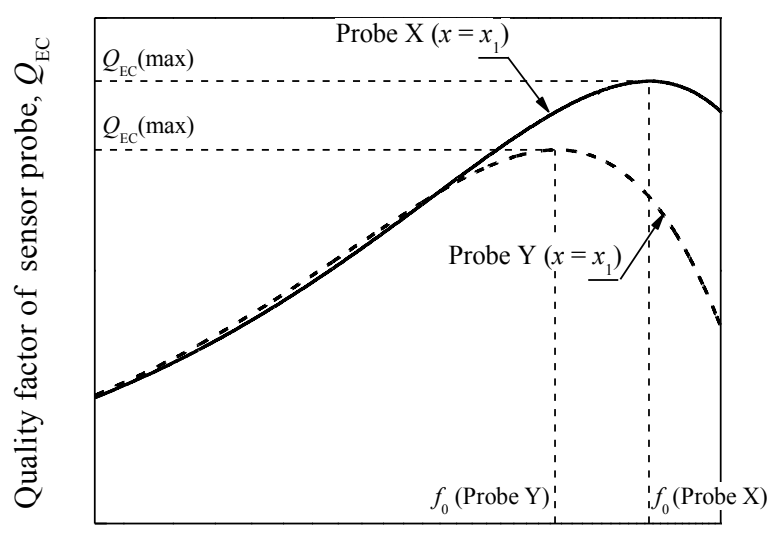

Frequency $f(\mathrm{~Hz})$

Fig. 2. Principle of identifying type of sensor probe $\left(x=x_{1}\right)$.

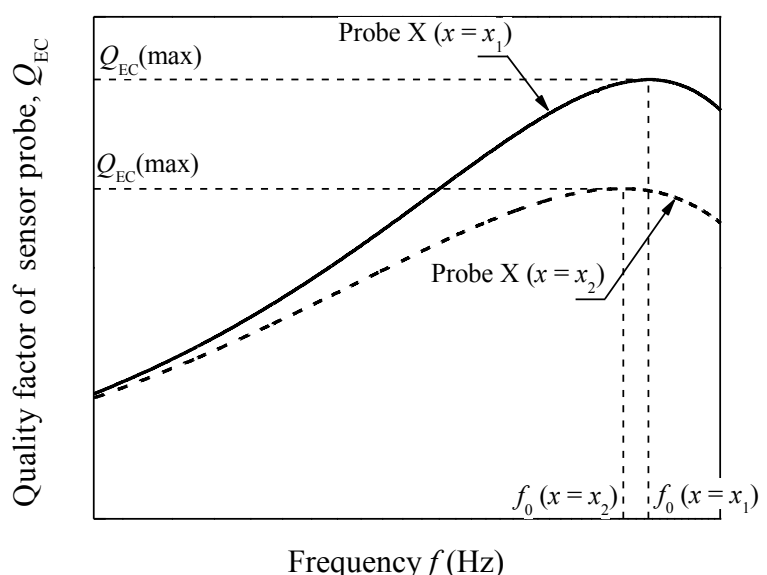

Fig. 3. Principle of identifying displacement $x$ (probe X).

Figs. 2 and 3 show the principles of identifying the type of the sensor probe and the displacement $x$, respectively. The quality factor of the sensor probe, $Q_{\mathrm{EC}}$, is given by [3]

$$
Q_{\mathrm{EC}}=\frac{\operatorname{Im}\left[Z_{\mathrm{EC}}\right]}{\operatorname{Re}\left[Z_{\mathrm{EC}}\right]}=\frac{\omega L_{\mathrm{EC}}}{R_{\mathrm{EC}}}
$$

where $\operatorname{Im}\left[Z_{\mathrm{EC}}\right]$ and $\operatorname{Re}\left[Z_{\mathrm{EC}}\right]$ are the imaginary and real parts of the impedance $(\Omega)$ of the sensor probe, respectively, $\omega$ is the angular frequency ( $=2 \pi f, \mathrm{rad} / \mathrm{s}$ ), $R_{\mathrm{EC}}$ is the resistance $(\Omega)$ of the sensor probe, $L_{\mathrm{EC}}$ is the inductance $(\mathrm{H})$ of the sensor probe, and $f$ is the exciting frequency $(\mathrm{Hz})$.

Fig. 2 shows the frequency characteristics on quality factor of two probe types, namely, Probe $\mathrm{X}$ and Probe $\mathrm{Y}$ at the displacement $x_{1} \cdot Q_{\mathrm{EC}}(\max )$ is the maximum quality factor, and $f_{0}$ is the frequency at the $Q_{\mathrm{EC}}$ largest. The impedance of the sensor probe changes depending on the structure of the sensor probe. For this reason, the identification of the sensor probe is possible by measuring and comparing the frequency characteristics of quality factor of Probe $\mathrm{X}$ and Probe $\mathrm{Y}$.

Fig. 3 shows the frequency characteristics of quality factor of Probe $\mathrm{X}$ at the displacements $x_{1}$ and $x_{2}$. The flux $\Phi_{\mathrm{e}}$ due to the eddy current $I_{\mathrm{e}}$, which flows in the measuring object, depends on the displacement $x$. For this reason, the resistance and inductance of the coil change with the displacement $x$. Therefore, the frequency characteristics of quality factor $Q_{\mathrm{EC}}$

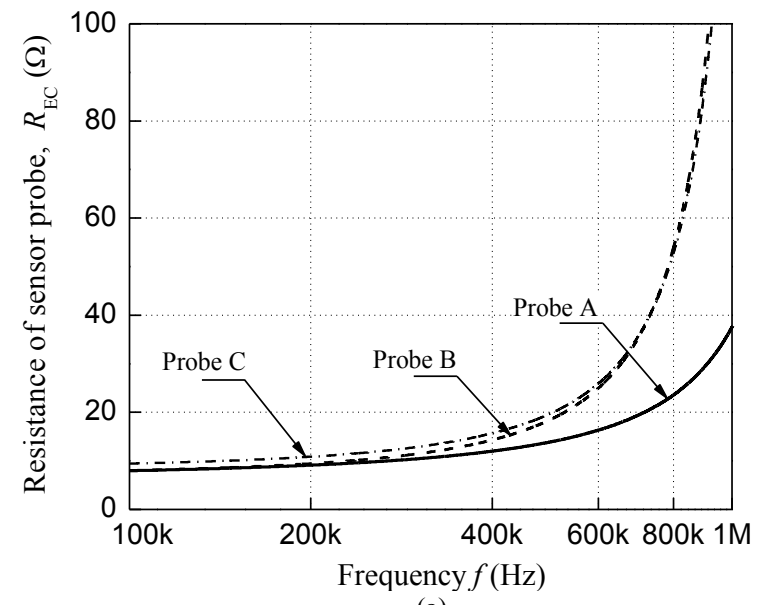

(a)

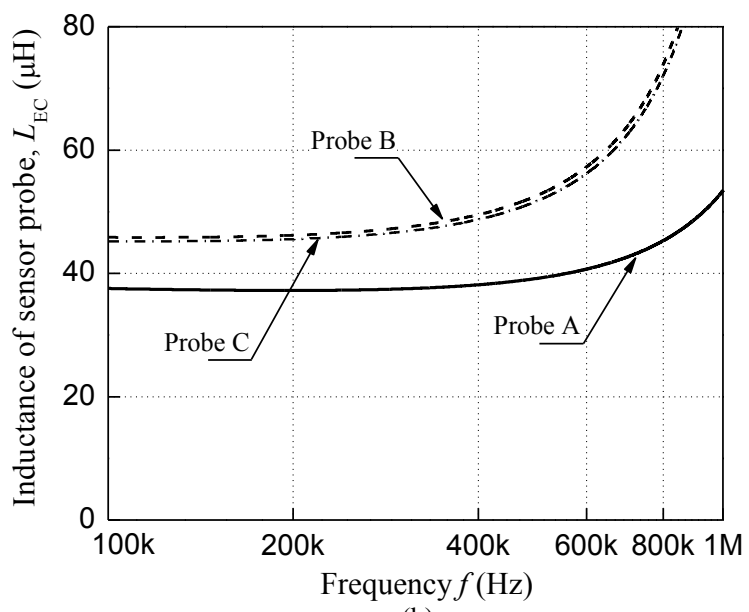

(b)

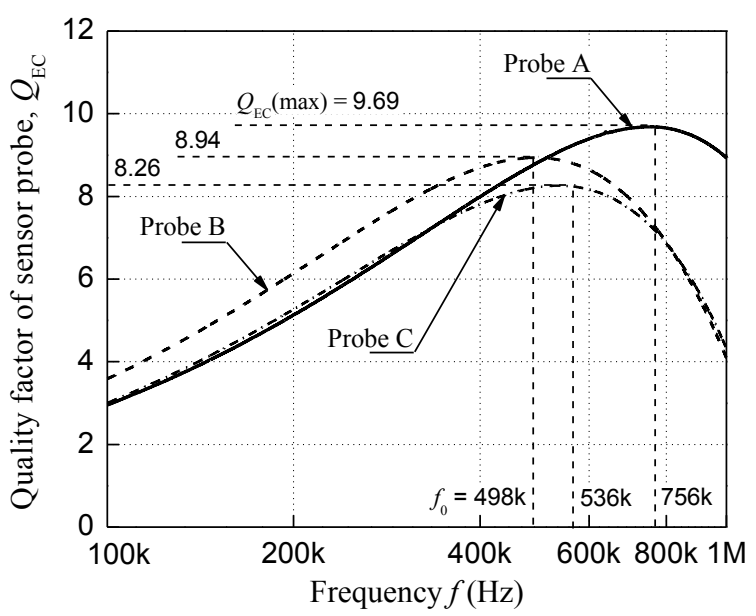

(c)

Fig. 4. Frequency characteristics of impedance of sensor probes with cable length $l_{\text {ca }}=5 \mathrm{~m}(x=1.3 \mathrm{~mm}, T=20$ degrees). (a) Resistance. (b) Inductance. (c) Quality factor.

depend on the displacement $x$. In brief, by measuring and comparing the frequency characteristics of quality factor $Q_{\mathrm{EC}}$ at the $x_{1}$ and $x_{2}$ of each sensor probes, it is also possible to identify the displacement $x$. 


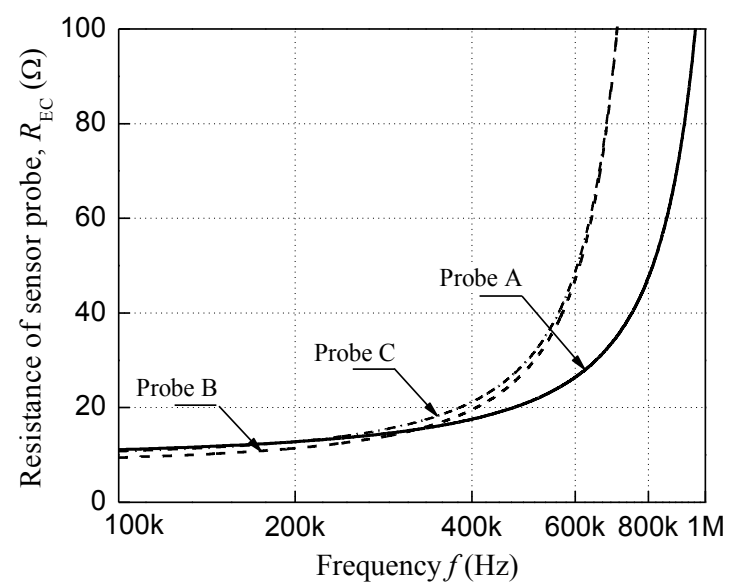

(a)

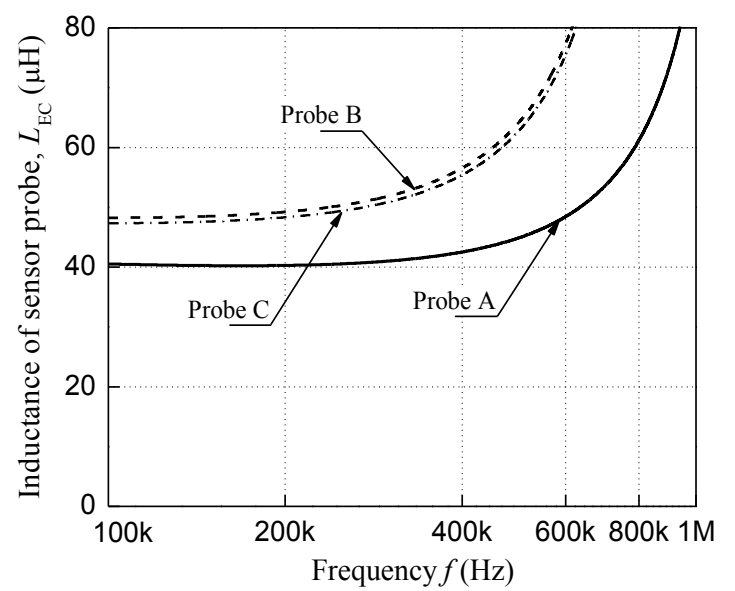

(b)

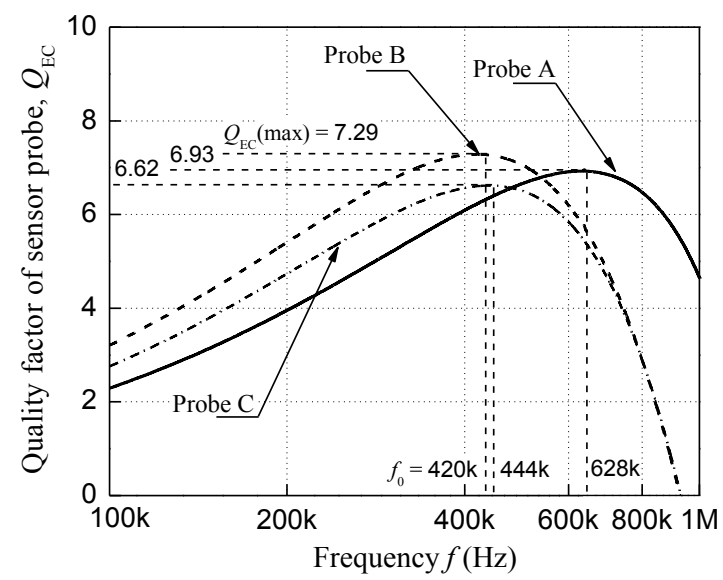

(c)

Fig. 5. Frequency characteristics of impedance of sensor probes with cable length $l_{\text {ca }}=9 \mathrm{~m}(x=1.3 \mathrm{~mm}, T=20$ degrees $)$. (a) Resistance. (b) Inductance. (c) Quality factor.

\section{RESUlts OF MEASUREMENTS}

\section{1) Identification of type of sensor probe}

Figs. 4 and 5 show the frequency characteristics of resistance $R_{\mathrm{EC}}$, inductance $L_{\mathrm{EC}}$ and quality factor $Q_{\mathrm{EC}}$ of the sensor probes with $5 \mathrm{~m}$ and $9 \mathrm{~m}$ coaxial cables at $x=1.3 \mathrm{~mm}$. $Q_{\mathrm{EC}}$ was calculated using equation (1).

Using an impedance analyzer (Agilent, 4294A), the

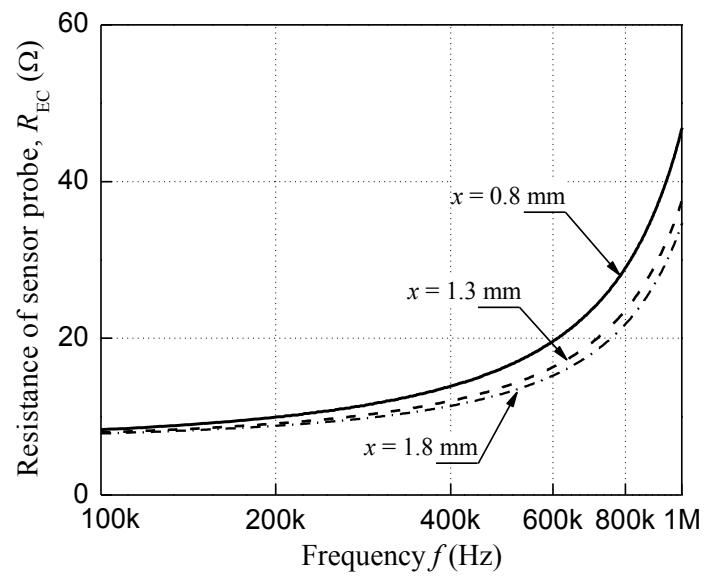

(a)

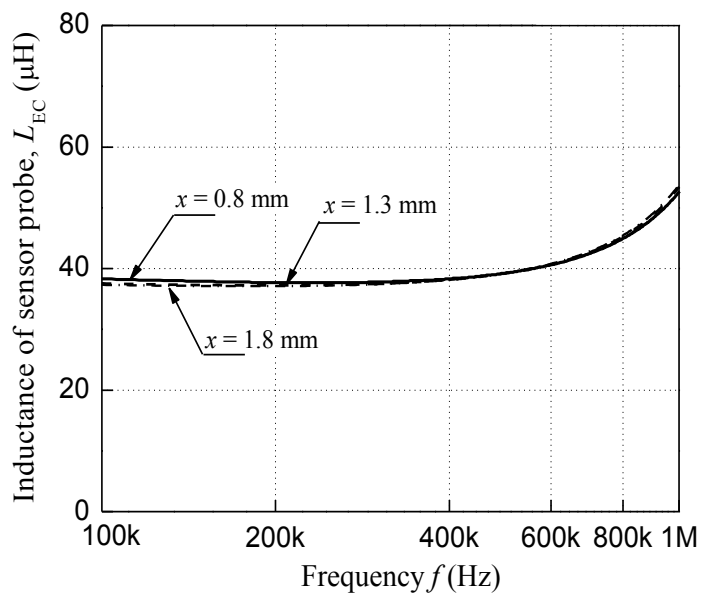

(b)

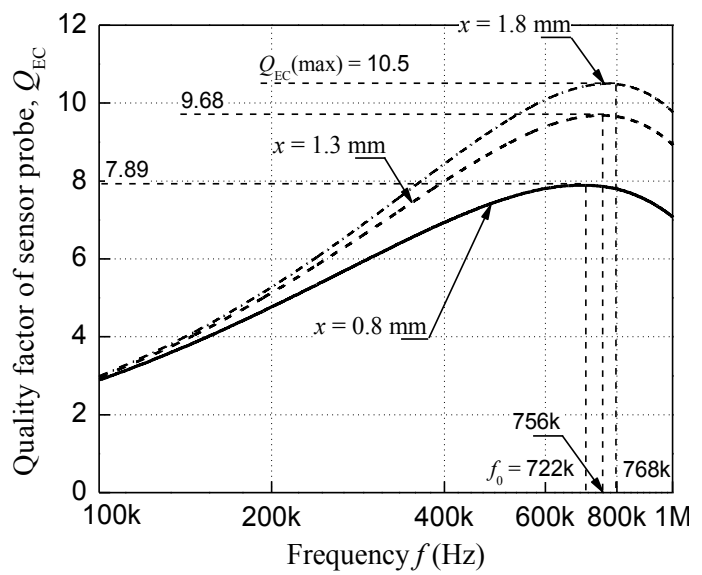

(c)

Fig. 6. Frequency characteristics of impedance of Probe A $\left(l_{\mathrm{ca}}=5 \mathrm{~m}\right.$, $T=20$ degrees). (a) Resistance. (b) Inductance. (c) Quality factor.

impedance characteristics are measured in the frequency range from $100 \mathrm{kHz}$ to $1 \mathrm{MHz}$. When the frequency characteristics of the sensor probe are measured, a portion $(200 \mathrm{~mm})$ of the sensor probe is placed in the temperature-controlled bath (Espec, SH-221). The temperature-controlled bath is set at 20 degrees. In Figs. 4 and 5, the frequency characteristics of $R_{\mathrm{EC}}$ and $L_{\mathrm{EC}}$ of Probe $\mathrm{B}$ and Probe $\mathrm{C}$ are similar. However, in Figs. 
4(c) and 5(c), the frequency characteristics of quality factor of the sensor probes differ. Therefore, the maximum quality factor $Q_{\mathrm{EC}}(\max )$ and the frequency $f_{0}$ at $Q_{\mathrm{EC}}(\max )$ differ with the type of the sensor probe. For this reason, the identification of the type of the sensor probe is possible.

\section{2) Identification of displacement $x$}

Fig. 6(a) - (c) show the frequency characteristics of $R_{\mathrm{EC}}, L_{\mathrm{EC}}$ and $Q_{\mathrm{EC}}$ of the Probe A with the cable length $l_{\mathrm{ca}}=5 \mathrm{~m}$. The measurement range of Probe A is $2 \mathrm{~mm}$, and the displacement is set from $0.8 \mathrm{~mm}$ within $1.8 \mathrm{~mm}$. Fig. 6 shows the frequency characteristics at $x=0.8,1.3$, and $1.8 \mathrm{~mm}$. In Fig. 6(a), when the displacement $x$ increases, the resistance $R_{\mathrm{EC}}$ decreases. When the displacement increases, the eddy current $I_{\mathrm{e}}$ in the measuring object decreases. Then the flux $\Phi_{\mathrm{e}}$ also decrease. For this reason, $Q_{\mathrm{EC}}$ increases. The maximum quality factor $Q_{\mathrm{EC}}(\max )$ and frequency $f_{0}$ at $Q_{\mathrm{EC}}(\max )$ differ with the displacement $x$, as shown in Fig. 6(c). Therefore, it is possible to identify the displacement $x$.

\section{IDENTIFICATION METHOD}

Fig. 7 shows the frequency $f_{0}$ characteristics of maximum quality factor of the sensor probes, $Q_{\mathrm{EC}}(\max )$ with the cable lengths $l_{\mathrm{ca}}=5 \mathrm{~m}$ and $9 \mathrm{~m}$. The $Q_{\mathrm{EC}}(\max )$ and $f_{0}$ were determined based on the frequency characteristics of quality

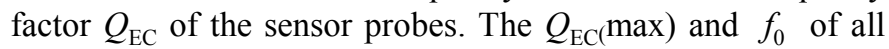
the sensor probes increase with the displacement $x$. Moreover, they differ with the type of the sensor probe and displacement $x$, as shown in Fig. 7. Therefore, when a sensor probe whose type and displacement $x$ are unknown is installed, the identification of the type of the sensor probe and displacement $x$ is possible by comparing the measured $Q_{\mathrm{EC}}(\max )$ versus $f_{0}$ characteristics of the sensor probe with those shown in Fig. 7. By using this method, when the power plant is operating, the identification of the type of the sensor probe and displacement $x$ becomes possible.

\section{CONCLUSION}

\section{1) Identification of type of sensor probe}

It was clarified that the $Q_{\mathrm{EC}}(\max )$ versus $f_{0}$ characteristics differ with the structure of the sensor probe. Therefore, the identification of the type of the sensor probe is possible by measuring and comparing the characteristics of the sensor probe, when the power plant is operating.

2) Identification of displacement $x$

The $Q_{\mathrm{EC}}(\max )$ versus $f_{0}$ characteristics differ with the displacement $x$. Therefore, the identification of the displacement $x$ is possible by measuring and comparing the characteristics of the sensor probe. By using this method, it was clarified that the identification of the displacement $x$ becomes possible, when the power plant is operating.

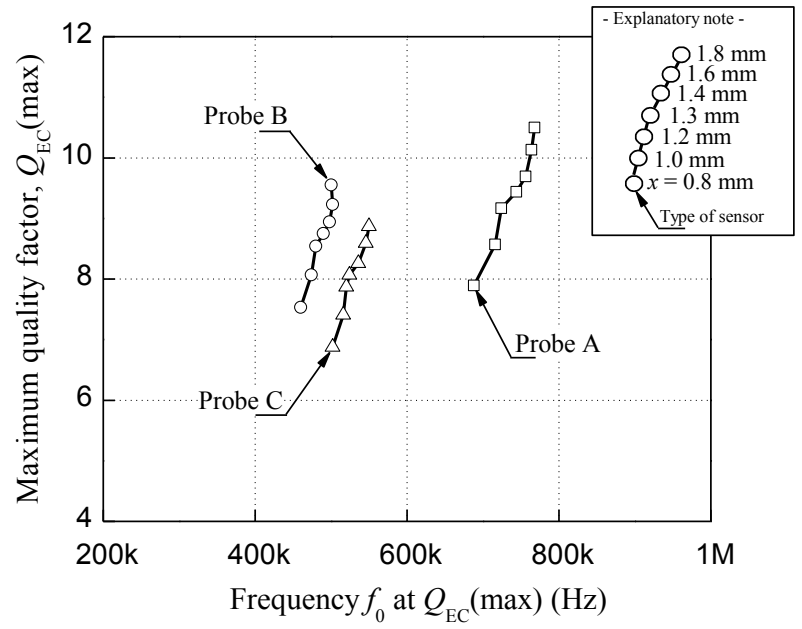

(a)

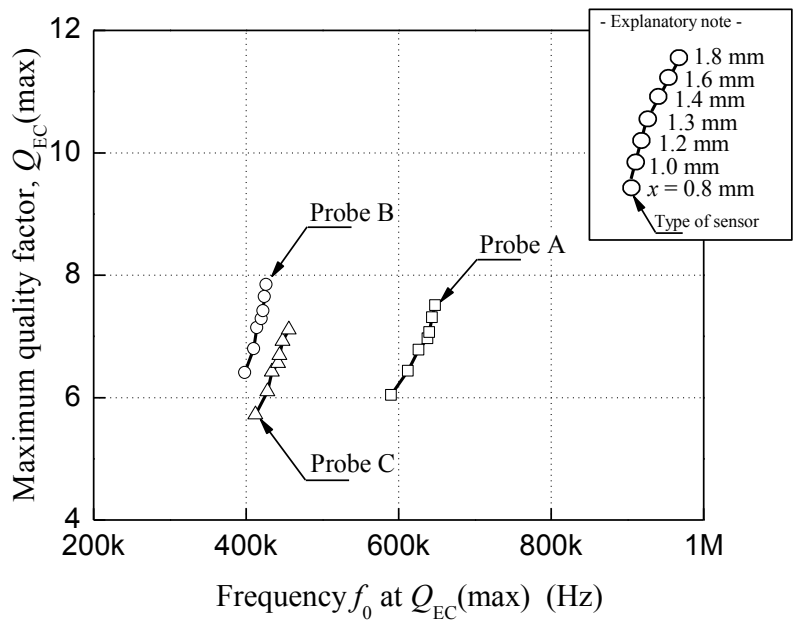

(b)

Fig. 7. Maximum quality factor $Q_{\mathrm{EC}}(\max )$ versus frequency $f_{0}$ at $Q_{\mathrm{EC}}(\max )$ characteristics of sensor probes. (a) $l_{\mathrm{ca}}=5 \mathrm{~m}$. (b) $l_{\mathrm{ca}}=9 \mathrm{~m}$.

\section{REFERENCES}

[1] American Petroleum Institute (API), Machinery Protection Systems, API670 4th Edition, pp. 23-27, 2000.

[2] T. Mizuno, K. Deguchi, Y. Kitamura, S. Enoki, H. Shinagawa, "Examination on length of coaxial cable for improvement in temperature drift of eddy-current displacement sensor," Asia Pacific of Applied Electromagnetics and Mechanics (APSAEM), Technical paper T13-02, pp. 430-435, 2010.

[3] H. Shinagawa, T. Suzuki, M. Noda, Y. Shimura, S. Enoki, T. Mizuno, "Theoretical analysis of $\mathrm{AC}$ resistance in coil using magnetoplated wire," IEEE Trans. on Magn. Vol. 45, No. 9, pp. 3251-3259, 2009. 